\title{
Plasmid-mediated rifampicin resistance in Pseudomonas fluorescens
}

\author{
S. CHANDRASEKARAN and D. LALITHAKUMARI
}

Environmental Biotechnology Programme, Centre for Advanced Studies in Botany, University of Madras, Madras 600-025, India

\begin{abstract}
Rifampicin is an antibiotic mostly used to treat tuberculosis and leprosy, and, occasionally, other diseases. Resistance is due to alterations in membrane permeability or to mutation in the rpoB gene coding for mRNA polymerase. Both these mechanisms originate via chromosomal mutation. However, a rifampicin-resistant Pseudomonas fluorescens strain harboured a multiresistance plasmid which transferred rifampicin resistance when transformed into $P$. putida or Escherichia coli. Rifampicin readily diffused into the sensitive cells of the $E$. coli and $P$. putida recipients, but the transformants with the plasmid, pSCL were resistant to the drug and did not accumulate it. Potassium cyanide restored the diffusion of rifampicin into the resistant cells, indicating that an efflux pump was involved in the resistance mechanism. The resistance of the transformants and the wild strain was also abolished in sphaeroplasts generated by EDTA lysozyme treatment. Analysis of membrane proteins by SDS-PAGE revealed the presence of two new proteins in the plasmid-containing cells of $E$. coli, $P$. putida and $P$. fluorescens and not in the plasmidfree cells. These may be involved in the efflux of rifampicin.
\end{abstract}

\section{Introduction}

Bacterial resistance to antibiotics is a serious clinical problem, because it increases the morbidity, mortality and costs associated with disease [1]. Resistance arises by three major mechanisms: (i) drug inactivation, (ii) reduced drug accumulation and (iii) target alteration [2]. Antibiotic resistance can be specified by chromosomal or plasmid-encoded genes. Plasmid-mediated resistance is the more serious, as plasmids allow horizontal transfer, disseminating resistance genes to other bacteria.

Rifampicin is effective against a wide spectrum of pathogens and is a valuable first-line drug for tuberculosis and leprosy [3]. It inhibits bacterial RNA synthesis by binding to the $\beta$-subunit of the DNA-dependent RNA polymerase [4]. Resistance mostly results from amino acid substitution, or small insertions and deletions, within three short highly conserved regions of the $\beta$-subunit of the RNA polymerase. These modifications decrease the affinity of the antibiotic for its target site [5]. Hui et al. [6] suggested that membrane impermeability might also mediate rifampicin resistance in some strains of Mycobacterium intracellulare, where the RNA poly-

Received 22 April 1997; revised version accepted 21 June 1997.

Corresponding author: Dr S. Chandrasekaran. merase itself remained susceptible. All these mechanisms reflect chromosomal changes [7], but the present study reports plasmid-mediated rifampicin resistance in Pseudomonas fluorescens.

\section{Materials and methods}

\section{Bacterial strains}

P. fluorescens CAS 102 was isolated from polluted soil It harboured a single large $140-\mathrm{kb}$ plasmid, $\mathrm{pSCL}$, encoding resistance to multiple antibiotics [8]. E. coli $\mathrm{HB} 101$ (supE44, ara14, galK2, lac $\mathrm{Y} 1$, recA13, proA2, mtl13, xy15) and P. putida DSM $2112\left(\mathrm{Str}^{+}\right.$, $\mathrm{Trp}^{-}$, plasmid-free) were from the Institute of Microbial Technology, Chandigargh, India. Cultures were grown in Luria Broth (tryptone $1 \%$, yeast extract $0.5 \%$, $\mathrm{NaCl} 0.5 \%)$ at $30^{\circ} \mathrm{C}$.

\section{Plasmid isolation and transformation techniques}

Plasmid DNA from $P$. fluorescens CAS 102 was isolated and resolved in agarose $0.6 \%$ gel electrophoresis at $50 \mathrm{~V}$ with TAE electrode buffer as described previously [8]. The DNA was visualised by staining the gel with ethidium bromide $(1 \mathrm{mg} / \mathrm{L})$ for $15 \mathrm{~min}$ and was photographed under short-wave UV light. Transformation of logarithmic-phase $E$. coli $\mathrm{HB} 101$ cells was performed by the calcium chloride procedure of 
Maniatis et al. [9], and plasmid-free $P$. putida cells were transformed as described by Berry and Kropinsky [10]. Transformants were selected in LB medium with tetracycline $25 \mathrm{mg} / \mathrm{L}$, chloramphenicol $25 \mathrm{mg} / \mathrm{L}$, gentamicin $25 \mathrm{mg} / \mathrm{L}$ or kanamycin $25 \mathrm{mg} / \mathrm{L}$. Transformants that could grow in the presence of all these antibiotics were then screened for resistance to rifampicin. Transformation was further confirmed by isolating the plasmid DNA from the transformants.

\section{Rifampicin uptake}

Rifampicin (Sigma) is a coloured substance with an absorbance peak at $473 \mathrm{~nm}$. The procedure of Nikaido et al. [11] was adopted, with modifications, to study its uptake by bacteria. Cells were grown overnight in Luria broth and harvested by centrifugation. They were washed once and resuspended in $0.1 \mathrm{M}$ phosphate

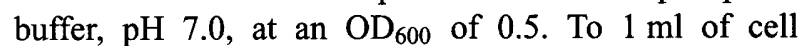
suspension, $50 \mu \mathrm{g}$ of rifampicin (from a $1 \mathrm{mg} / \mathrm{ml}$ stock solution in methanol) was added, and the decrease in $\mathrm{OD}_{473}$ was recorded continuously with a Philips PU $8740 \mathrm{UV} / \mathrm{Vis}$ Scanning Spectrophotometer. In some tests potassium cyanide was added to the cell suspension to a final concentration of $0.1 \mathrm{M}$.

\section{Formation of sphaeroplasts}

Sphaeroplasts were prepared by the procedure of Nikaido [12], with slight modifications. Organisms were grown overnight in Luria broth and harvested by centrifugation at $6000 \mathrm{~g}$ for $10 \mathrm{~min}$ at $4^{\circ} \mathrm{C}$. The cells, at a density of $10 \mathrm{mg}$ wet weight $/ \mathrm{mL}$, were suspended in $45 \mathrm{ml}$ of icecold $0.75 \mathrm{M}$ sucrose in $0.01 \mathrm{M}$ Tris- $\mathrm{HCl}$ buffer, $\mathrm{pH}$ 7.5. After mixing, $5 \mathrm{~mL}$ of sucrose in Tris buffer containing lysozyme (Sigma) $10 \mathrm{mg}$ were added. This was followed by incubation for $2 \mathrm{~min}$ at $0^{\circ} \mathrm{C}$, then the suspension was diluted by adding $100 \mathrm{ml}$ of ice-cold water over $5 \mathrm{~min}$, with constant stirring. The suspension was then centrifuged at $3000 \mathrm{~g}$ for $10 \mathrm{~min}$ at $4^{\circ} \mathrm{C}$. The pellet was carefully resuspended in $1.5 \mathrm{ml}$ of $0.25 \mathrm{M}$ sucrose in $0.01 \mathrm{M}$ Tris- $\mathrm{HCl}$ buffer, $\mathrm{pH} 7.5$ and equilibrated to $14^{\circ} \mathrm{C}$ in a water-bath, after which $0.3 \mathrm{ml}$ of $0.25 \mathrm{M}$ sucrose containing $0.05 \mathrm{M}$ EDTA was added. The formation of sphaeroplasts was confirmed by microscopy, then rifampicin $50 \mathrm{mg} / \mathrm{L}$ was added, and the course of uptake was recorded as for intact cells (above).

\section{Analysis of outer-membrane proteins}

Outer membrane proteins (OMPs) were prepared as described by Cohen et al. [13], and resolved by SDSPAGE [14] in gels containing acrylamide $10 \%$. Proteins were visualised by staining with silver nitrate [15].

\section{Results}

P. fluorescens CAS 102 was resistant to rifampicin and to many antibiotics, dyes and heavy metals [8]. The rifampicin MIC, initially around $20 \mathrm{mg} / \mathrm{L}$, increased when the antibiotic concentration was incrementally raised over time. The organism harboured a single 140$\mathrm{kb}$, plasmid designated pSCL, which was extremely recalcitrant to curing. Hence, to understand the basis of rifampicin resistance, two plasmid-free bacterial strains, i.e., E. coli $\mathrm{HB} 101$ and $P$. putida DSM 2112 , were transformed with pSCL. These recipients initially were sensitive to rifampicin (MIC $<5 \mathrm{mg} / \mathrm{L}$ ), but became resistant after transformation. They, like $P$. fluorescens CAS 102, also became resistant to tetracycline, gentamicin, kanamycin and chloramphenicol. Isolation of plasmid DNA from the transformants confirmed the presence of pSCL. Moreover, they, unlike $P$. fluorescens CAS 102, were amenable to curing, losing the plasmid upon repeated subculture in nutrient broth. After curing, these cultures became sensitive to rifampicin, tetracycline, gentamicin, kanamycin and chloramphenicol.

To determine the mechanism of resistance, the plasmid-free and transformed $E$. coli and $P$. putida, cells and $P$. fluorescens CAS 102 were assayed for rifampicin uptake (Fig. 1). The antibiotic readily diffused into the plasmid-free $E$. coli, and $P$. putida cells, as indicated by the decrease in $\mathrm{OD}_{473}$, but there was no uptake by the transformant cells nor by $P$.
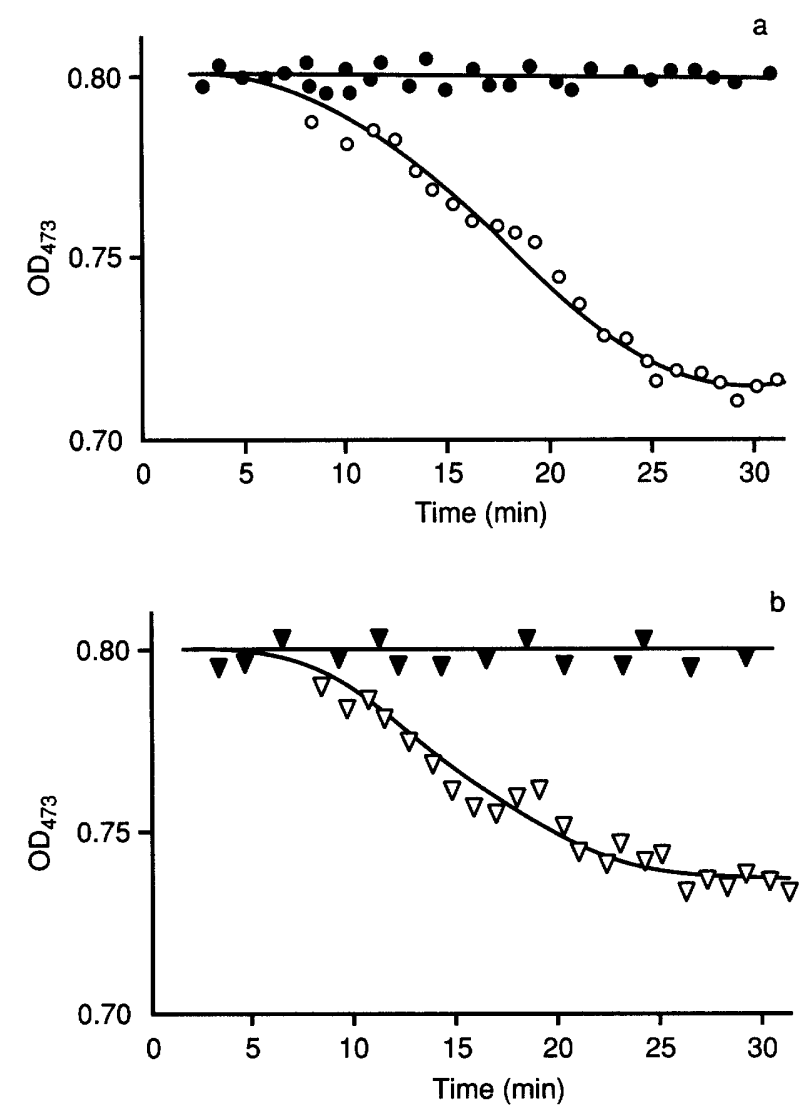

Fig. 1. (a) Rifampicin uptake by the plasmid-free cells of $E$. coli (O) and their transformants (O); (b) rifampicin uptake by the plasmid-free $P$. putida cells $(\nabla)$ and their transformants $(\nabla)$. 
fluorescens CAS 102. To confirm that the decrease in $\mathrm{OD}_{473}$ was due to permeation of the drug, sensitive cells of $E$. coli and $P$. putida were centrifuged after incubation for $30 \mathrm{~min}$ with rifampicin $50 \mathrm{mg} / \mathrm{L}$, washed in phosphate buffer and immediately sonicated. Debris was removed by centrifugation $(6000 \mathrm{~g}$ at $4^{\circ} \mathrm{C}$ for $10 \mathrm{~min}$ ). The supernates of the $E$. coli and $P$. putida sonicates contained 4.2 and $3.5 \mu \mathrm{g}$ of rifampicin $/ \mathrm{mg}$ dry cells, respectively. These values did not exactly match the original decline in absorbance, and a proportion of antibiotic may have been lost during processing. When transformed cells of $E$. coli and $P$. putida strains were treated similarly the sonicates contained negligible quantities of rifampicin.

When suspensions of $P$. fluorescens CAS 102 and transformants of $E$. coli and $P$. putida were incubated with potassium cyanide, as an energy uncoupler, rifampicin readily entered into the cells (Fig. 2). This result confirmed that resistance was due to efflux rather than simple exclusion. When plasmid-free cells of $E$. coli and $P$. putida were incubated with potassium cyanide, reduction in the $\mathrm{OD}_{473}$ was observed, indicating that the drug entered the cells by diffusion.

The OMPs of the plasmid-free and transformed $E$. coli and $P$. putida cells, and the wild strain $P$. fluorescens were examined by SDS-PAGE. Changes were evident in transformants, with the appearance of two new proteins, which were not present in the plasmid-free strains (Fig. 3). These were designated Rir proteins (rifampicin-resistance proteins) and were produced irrespective of the presence or absence of rifampicin. The presence of the plasmid also repressed expression of two $c$. $29-\mathrm{kDa}$ proteins in the $P$. putida transformant.

To confirm that resistance was solely due to efflux, resistant cells were converted to sphaeroplasts by lysozyme-EDTA treatment. Once the outer membrane

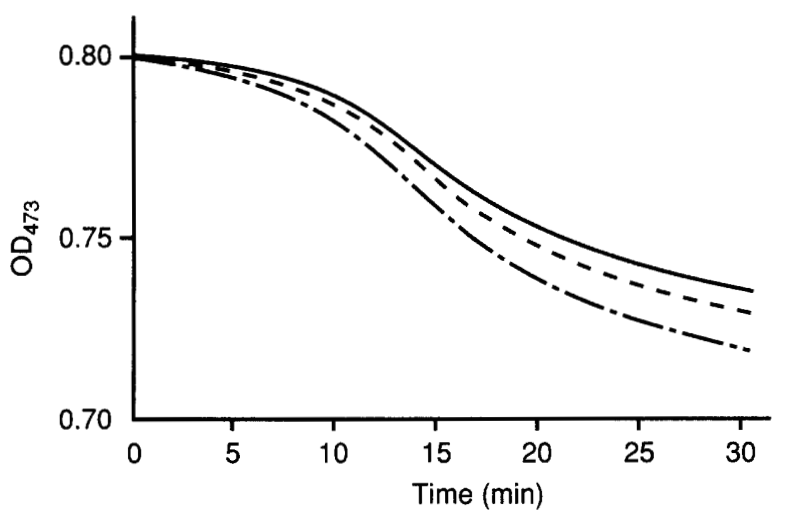

Fig. 2. Rifampicin uptake by $P$. fluorescens CAS 102 $(-)$ and the resistant transformants of E. coli $(-\cdot-)$ and $P$ putida $(--)$ in the presence of potassium cyanide.

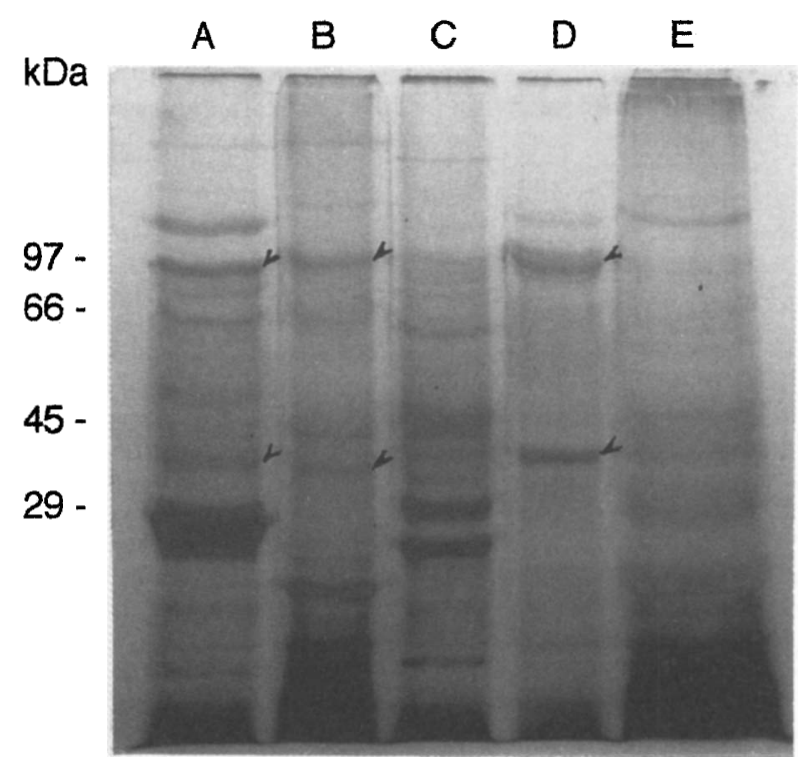

Fig. 3. SDS-PAGE of membrane proteins of P. fluorescens CAS 102 (lane A), $P$. putida transformed with pSCL (B), plasmid-free $P$. putida (C), E. coli HB101 with pSCL (D), plasmid-free E. coli HB101 (E). Arrows indicate the Rir proteins. Numbers on the left denote mol. wts.

barrier was removed by this process, it was observed that the rifampicin readily diffused into the cells. However, the rate of uptake by the sphaeroplasts of both $E$. coli and $P$. putida transformants was slightly less than by the intact plasmid-free sensitive cells. Uptake was further confirmed by release of diffused rifampicin from the sphaeroplasts of the transformants: sonicates of the $E$. coli and $P$. putida sphaeroplasts contained 3.1 and $2.2 \mu \mathrm{g}$ of rifampicin $/ \mathrm{mg}$ dry mass, respectively. Uptake of $2.1 \mu \mathrm{g}$ of rifampicin $/ \mathrm{mg}$ dry cells was also observed for the sphaeroplasts of $P$. fuorescens CAS 102.

\section{Discussion}

Rifampicin is a hydrophobic antibiotic and enters bacteria by dissolving into the hydrocarbon interior of the outer membrane and then diffusing into the aqueous phase of the periplasm. Finally, it diffuses across the cytoplasmic membrane [12]. Resistance may arise by alteration in the outer membrane structure, as reported for a mutant of Neisseria meningitidis, where a significant decrease in the amount of $\mathrm{C}_{16}$ outer membrane lipids appeared to be responsible [16]. Resistance may also arise by a single point mutation in the short central region of the $r p o B$ gene, which codes for RNA polymerase [4]. However, in the present case, the results show that the resistance was due to plasmid-encoded OMPs.

Association between the production of novel OMPs and resistance to antimicrobial agents is well established. For example, $P$. aeruginosa with $n f x \mathrm{C}$ and 
$n f x \mathrm{~B}$ mutations $[17,18]$ show decreased susceptibility to several antimicrobial agents and concomitant production of $54-$ and $50-\mathrm{kDa}$ OMPs, respectively. Poole et al. [19] reported that decreased drug accumulation by these mutants was not due to reduced outer membrane permeability, as originally suggested, but to efflux. It is now agreed that even the most effective permeability barrier could not effectively exclude small molecules, unless a second factor, in the form of drug inactivation or efflux is present [20]. The present study suggests participation of an efflux pump in rifampicin resistance, as addition of potassium cyanide would de-energise such a pump, leading to the diffusion of the antibiotic into the resistant cells-as was seen.

Unlike the mammalian multi-drug efflux pump, Pglycoprotein, which is ATP-dependent, most bacterial multidrug efflux pumps are driven by the proton motive force (PMF) of the transmembrane electrochemical gradient. The fact that cyanide abolished efflux in the present case implies that the rifampicin efflux pump reported here could belong to this category. PMF-dependent efflux pump systems may comprise OMPs as small as $15 \mathrm{kDa}$ belonging to the $s m r$ family [21] or they may comprise multicomponent efflux machinery which includes proteins belonging to the major facilitator superfamily (MFS) or the resistance/nodulation/cell division (RND) family [22]. It is not clear whether the two membrane proteins reported here confer resistance only to rifampicin by selective efflux, as, e.g., with tetracycline transporters, or against a wide range of structurally dissimilar compounds as with some of the $P$. aeruginosa systems [19]. Plasmid pSCL codes for resistance to a large number of antibiotics, heavy metals and dyes and further biochemical and genetic analysis will reveal more about its function and nature.

We thank Professor A. Mahadevan for the facilities and Council of Scientific and Industrial Research, Government of India for the financial assistance.

\section{References}

1. Cohen ML. Epidemiology of drug resistance: implications for a postantimicrobial era. Science 1992; 257: 1050-1055.

2. Neu HC. The crisis of antibiotic resistance. Science 1992; 257: $1064-1073$.
3. Kucers A, Bennet $N$ McK. Rifampicin (Rifampicin). In: The use of antibiotics. A comprehensive review with clinical emphasis, 3rd edn. London, William Heinemann. 1979: 552584.

4. Spratt BG. Resistance to antibiotics mediated by target alterations. Science 1994; 264: 388-393.

5. Severinov K, Soushko M, Goldfarb A, Nikiforov V. Rifampicin region revisited: new rifampicin-resistant and streptolydiginresistant mutants in the $\beta$-subunit of Escherichia coli RNA polymerase. J Biol Chem 1993; 268: 14820-14825.

6. Hui J, Gordon N, Kajioka R. Permeability barrier to rifampicin in mycobacteria. Antimicrob Agents Chemother 1977; 11: 773779.

7. Cohen SP, Yan W, Levy SB. A multidrug resistance regulatory chromosomal locus is widespread among enteric bacteria. $J$ Infect Dis 1993; 168: 484-488.

8. Chandrasekaran S, Lalithakumari D. Plasmid-assisted morpholine degradation by Pseudomonas fuorescens CAS 102. World $J$ Microbiol Biotechnol 1997 (in press).

9. Maniatis T, Fritsch EF, Sambrook J. Molecular cloning: a laboratory manual. Cold Spring Harbor, NY. Cold Spring Harbor Laboratory. 1982.

10. Berry D, Kropinski AM. Effect of lipopolysaccharide mutations and temperature on plasmid transformation efficiency in Pseudomonas aeruginosa. Can J Microbiol 1986; 32: 436438.

11. Nikaido H, Rosenberg EY. Cir and Fiu proteins in the outer membrane of Escherichia coli catalyze transport of monomeric catechols: study with $\beta$-lactam antibiotics containing catechol and analogous groups. $J$ Bacteriol 1990; 172: 1361-1367.

12. Nikaido H. Outer membrane of Salmonella typhimurium: transmembrane diffusion of some hydrophobic substances. Biochim Biophys Acta 1976; 433: 118-132.

13. Cohen SP, McMurry LM, Levy SB. marA locus causes decreased expression of OmpF porin in multiple-antibioticresistant (Mar) mutants of Escherichia coli. J Bacteriol 1988; 170: $5416-5422$.

14. Laemmli UK. Cleavage of structural proteins during the assembly of the head of Bacteriophage T4. Nature 1970; 227: $680-685$.

15. Nesterenko MV, Tilley M, Upton SJ. A simple modification of Blum's silver stain method allows for 30 minute detection of proteins in polyacrylamide gels. $J$ Biochem Biophys Methods 1994; 28: 239-242.

16. Abadi FJR, Carter PE, Cash P, Pennington TH. Rifampicin resistance in Neisseria meningitidis due to alterations in membrane permeability. Antimicrob Agents Chemother 1996; 40: $646-651$.

17. Fukuda $H$, Hosaka $M$, Hirai $K$, Iyobe $S$. New norfloxacin resistance gene in Pseudomonas aeruginosa PAO. Antimicrob Agents Chemother 1990; 34: 1757-1761.

18. Hirai K, Suzue S, Irikua T, Iyobe S, Mitsuhashi S. Mutations producing resistance to norfloxacin in Pseudomonas aeruginosa. Antimicrob Agents Chemother 1987; 31: 582-586.

19. Poole K, Krebes K, McNally C, Neshat S. Multiple antibiotic resistance in Pseudomonas aeruginosa: evidence for involvement of an efflux operon. $J$ Bacteriol 1993; 175: 7363-7372.

20. Nikaido $H$. Prevention of drug access to bacterial targets: permeability barriers and active efflux. Science 1994; 264: $382-388$.

21. Grinius LL, Goldberg EB. Bacterial multidrug resistance is due to a single membrane protein which functions as a drug pump. $J$ Biol Chem 1994; 269: 29998-30004.

22. Paulsen IT, Brown MH, Skurray RA. Proton-dependent multidrug efflux systems. Microbiol Rev 1996; 60: 575-608. 